\title{
THYMOMA WITH LATERAL AND PARACARDIAC EVOLVEMENT
}

\author{
Oana-Raluca Lucaciu $^{1 凶}$, P.V-H. Boțianu ${ }^{1}$, T. Hogea ${ }^{1}$ \\ Claudia Dorobăț ${ }^{2}$, A-M. Boțianu ${ }^{1}$ \\ 1) Department of Surgery, University of Medicine and Pharmacy Tg. Mureş, Romania \\ 2) Department of Radiology, Emergency Clinic County Hospital Tg. Mureş, Romania
}

\begin{abstract}
THYMOMAS WITH LATERAL AND PARACARDIAC EVOLVEMENT (Abstract): Thymoma is the most common tumor of the anterior mediastinum originating from epithelial thymic cells. The tumors are often asymptomatic or with non specific symptoms. We present herein three cases admitted in our surgical for mediastinal tumor. The imagery exams revealed thymomas with lateral and paracardiac evolvement. Intraoperatively, we found tumors in closed contact with the pericardium, developed posterior to the phrenic nerve. In all cases, we performed complete excision of the tumors using a posterolateral thoracotomy. Frozen section was inconclusive in all cases; the final pathological exam diagnosed stage I thymoma. The postoperative course was uneventful for all three patients. The long term follow-up (14 years) revealed no recurrence.
\end{abstract}

\section{KEY WORDS: THYMOMA; MEDIASTINAL TUMORS; THORACOTOMY.}

SHORT TITLE: Lateral \& paracardiac thymoma

HOW TO CITE: Lucaciu OR, Boțianu PVH, Hogea T, Dorobăț C, Boțianu AM. Thymoma with lateral and paracardiac, evolvement. Jurnalul de chirurgie (Iaşi). 2013; 9(2): 173-178. DOI: 10.7438/1584-9341-9-2-9.

\section{INTRODUCTION}

Thymoma is a tumor originating from epithelial thymus cells, the thymocytes [1]. Most often it is located in anterior mediastinum (95\%); other sites as cervical region, pulmonary hilar regions, lung parenchyma, visceral mediastinum, cardiophrenic angle, paravertebral sulcus, tracheal wall (like a tracheal polyp appearance) are also noted [2].

Thymoma is often asymptomatic and diagnosed incidentally during a routine thoracic X-ray exam or associated with signs of mediastinal compression (superior vena cava syndrome, dysphagia, dyspnea, chest pain); in 30 to $45 \%$ it is associated with myasthenia gravis [2].

During the last 15 years we had 3 cases referred to our unit with the diagnosis of mediastinal / pulmonary tumor, where the preoperative imagery showed a mediastinal tumor, with lateral-paracardiac evolvement.

\section{Case 1}

A 47 years old woman was admitted in our service for chest pain, medium dyspnea and irritating cough. The symptoms started three months before. On admission, physical exam found no other pathological aspects. The thoracic X-ray exam showed a round opacity in the $1 / 2$ upper chest, over the heart near the intersection with large vessels (Fig. 1). Computed tomography (CT) showed a solid mass in the superior mediastinum, well defined, encapsulated; ultrasound exam revealed no pericardial and pleural fluid.

After conducting interdisciplinary preoperative pulmonology and cardiology checkups and achieving a proper preoperative preparation, the surgical intervention was performed under general anaesthesia with orotracheal intubation.

Intraoperatively, we performed a posterolateral thoracotomy that gave us an 
excellent exposure; we found a well delimitated and encapsulated tumor in closed contact with the pericardium, developed posterior to the phrenic nerve and we performed the complete tumor removal.

The patient postoperative course was uneventful and was discharged after 10 days. The follow-up revealed no recurrence during 6 years after the surgical procedure.

Frozen histopathological examination was inconclusive; the diagnosis was made by final histopathology that showed no atypical cells - stage Masaoka I.

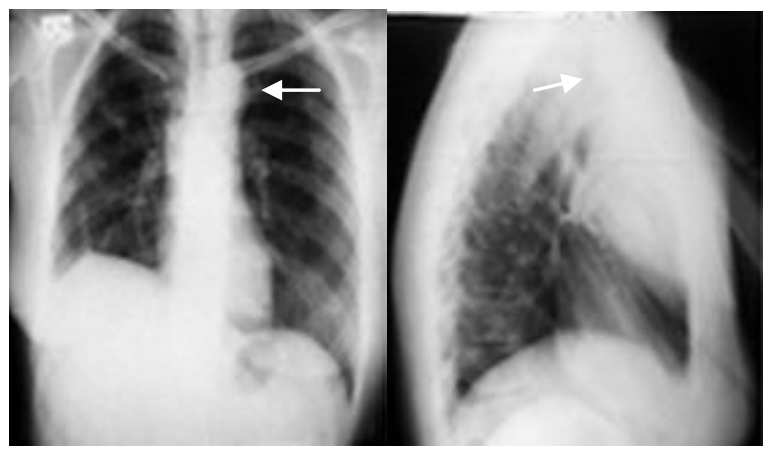

Fig. 1 Case 1: Thoracic X-ray exam: opacity in superior mediastinum

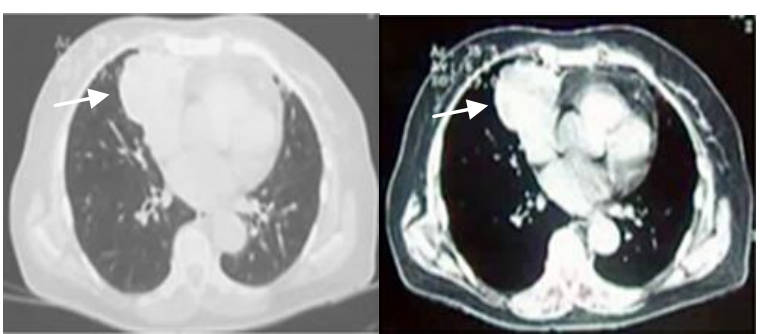

Fig. 2 Case 2: CT scan: solid mass in anterior mediastinum with lateral and paracardiac evolvement

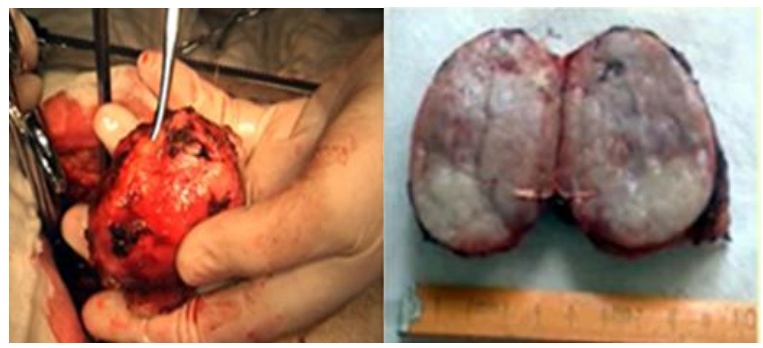

Fig. 3 Case 2: Resected secimen

Case 2

A 70 years old woman was admitted in our surgical unit for irritating dry cough, dyspnea, hoarseness, night sweats and pain in the right hemithorax. The thoracic X-ray exam revealed opacity in the lower half of the chest with extension to the straight hemithorax.

The CT scan shows a solid mass in the anterior mediastinum well defined, encapsulated, developed posterior to the phrenic nerve (Fig. 2).

Surgical excision was made using also a posterior lateral thoracotomy, with the complete removal of the tumor (Fig. 3).

The postoperative course was also uneventful and the patient was discharged day $14^{\text {th }}$. No recurrence has been noted 14 years after surgical procedure. The pathological exam showed no atypical cells (stage Masaoka I).

\section{Case 3}

A 46 years old woman was admitted in our surgical department for non specific symptoms: diffuse chest pain, irritating dry cough and loss of appetite. From she's past medical history we noted the hysterectomy performed 5 years ago. On admission, physical exam found no other pathological aspects.

Thoracic X-ray exam showed an oval opacity in the lower half of the chest with extension to the right hemithorax (Fig. 4). CT scan confirmed a well defined, encapsulated, solid mass, without pericardial and pleural fluid (Fig. 5).

After conducting interdisciplinary preoperative pulmonology and cardiology and oncological checkups, and achieving a proper preoperative preparation, the surgery was performed under general anaesthesia with orotracheal intubation.

We performed an antero-lateral thoracotomy; a well delineated and encapsulated tumor in close contact with the pericardium was found and the complete removal of the tumor was performed (Fig. 6).

Frozen sections were inconclusive; the pathological exam revealed lymphocyte cell thymoma (stage Masaoka I).

The postoperative course was uneventful and we have not met any recurrence after 9 years. 


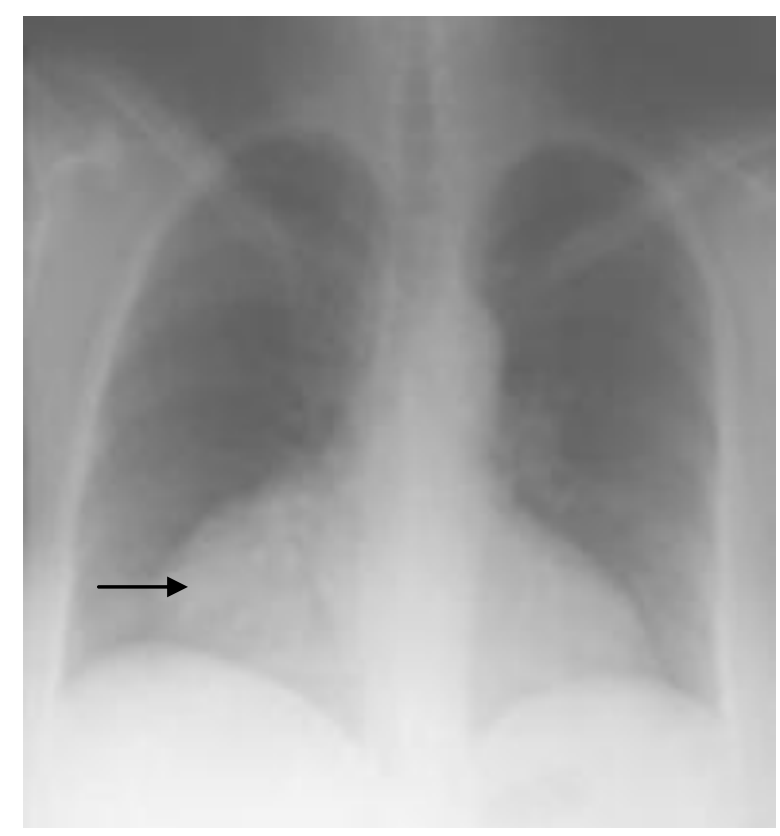

Fig. 4 Case 3: Oval opacity in the lower half of the chest with extension to the right hemithorax

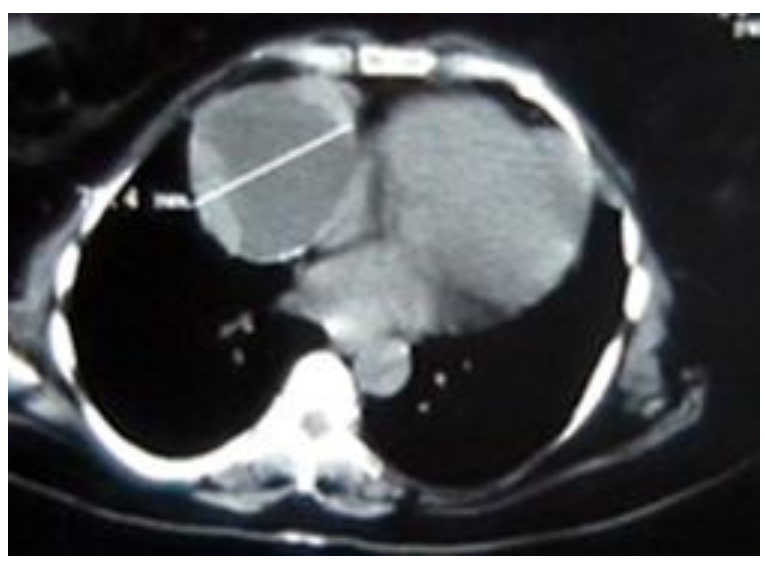

Fig. 5 Case 3: Lateral and paracardiac tumor

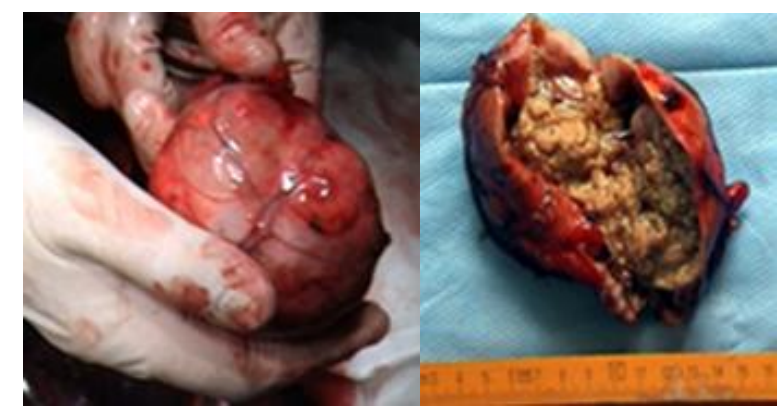

Fig. 6 Case 3: Resected specimen

\section{DISCUSSION}

Thymoma, the most common tumor of the mediastinum represents $20-25 \%$ of all mediastinal tumors and $50 \%$ of overall mediastinal masses [5]. Maximum incidence of thymoma is in the fourth or fifth decade of life; the patients average age is 52 [5]. The incidence is similar in women and in men [5]. In our study, all cases were women averaging $54.33 \pm 13.33$ years old.

Although the development of thymoma in childhood is rare, the symptoms are more frequent in children than in adults [6].

About $50 \%$ of patients with thymoma are asymptomatic [7]. Non specific symptoms are noted like chest pain, cough and dyspnea [7]. More severe symptoms such as superior vena cava syndrome, phrenic nerve paralysis or recurrent laryngeal nerve paralysis that causes raucous voice are rare and most frequently indicates malignancy of the lesion [6]. Chest wall or pleural invasion can also occur in the case of amalignant thymoma, frequently accompanied by persistent pleural effusion and significant local pain [6].

Other general signs associated with thymoma are weight loss, fever, fatigability and night sweats and were present in $20 \%$ of patients included [7].

Myasthenia gravis is a relatively rare disease and can occur at any age. Women are affected more frequently than men, with peak incidence around 30 years old; the peak incidence in men is reached at the age of 5060 years. Surgical treatment of myasthenia is the thymectomy. Remission rate increases in time reaching $40-60 \%$ at $7-10$ years after the surgery [2].

Posteroanterior (PA) and lateral chest X-ray exams can detect most of thymomas. On the PA view, the lesion typically appears as a smooth mass in the upper half of the chest, overlying the superior portion of the cardiac shadow near the junction of the heart and great vessels. The mass usually projects predominantly into one of the hemi thoraces. On the right side, the silhouette sign is present and the ascending portion of the aortic arch is obliterated. Conversely, if the thymoma is on the left side, the silhouette sign is obscured and the aortic knob is identified behind the mass [7].

CT scan may delineate a mass further or detect a smaller tumor missed on 
radiography. CT scan is the gold standard imaging procedure in patients with miastenia gravis. Thymic enlargement should be determined because most enlarged thymus glands on CT scan represent a thymoma. CT scanning with intravenous contrast dye is mandatory and shows the relationship between thymoma and surrounding vascular structures; it also defines the vascularity pattern and assists the surgeon to plan the surgical procedure to completely remove the tumor [7].

Positron emission tomography (PET) has proven to be invaluable in confirming the diagnosis of malignant invasive thymoma. Although CT may reveal evidence of anterior mediastinal masses, PET scan shows the hypermetabolic activity, thus the suspicion of malignancy. PET should be added as a diagnosis method to help the surgeon in determining the adequate stage and involvement of other structures [8].

Preoperative histological diagnosis can be achieved through biopsy by mediastinoscopy, thoracoscopy or CT guided transparietal biopsy [9].

With reference to histology, there is no clear distinction between benign or malignant thymoma. The trend of a benign or malignant thymoma is determined by its invasive character. Malignant thymoma invades the great vessels, lymphatics and adjacent areas of the mediastinum structures. The survival rate of people with invasive thymoma for a 15 year-period is $12.5 \%$ and $47 \%$ for a person with non-invasive thymoma. Death usually occurs by cardiac tamponade or other cardio-respiratory complications [10].

Usually thymoma are classified using Masaoka Staging System (Table I) [3].

The histological type is also essential for the prognosis; so, for medullary and mixed thymoma the disease free survival rate is $100 \%$ and decreased to $28 \%$ for thymic carcinoma (Table II) [4,5].

Several reports from the literature suggest that benign or malignant thymomas are chemosensitive tumors. Potential candidates for chemotherapy include approximately one third of the patients with invasive thymoma, metastasis and all patients with stage IV disease. Fornasiero A et al. [5] reported successful long-term survival following treatment with cisplatin + vincristine + doxorubicin + cyclophosphamide for invasive Thymoma incompletely resected or inoperable cases. Out of 32 patients, $90 \%$ have responded to therapy with a mean survival of 15 months. A study performed by the European Organisation for Research and Treatment of Cancer reported that in 16 cases of patients with recurrent or metastatic thymoma, were observed five complete remissions and four partial remissions. The median survival in this study was 4.3 years. [11]

Table I Masaoka Staging System of thymomas [3]

\begin{tabular}{lll}
\hline Stage & \multicolumn{1}{c}{ Definition } & \multicolumn{1}{c}{ Treatment } \\
\hline I & $\begin{array}{l}\text { Encapsulated tumor } \\
\text { with no gross or } \\
\text { microscopic invasion } \\
\text { Macroscopic invasion } \\
\text { into the mediastinal } \\
\text { fat or pleura or } \\
\text { Microscopic invasion } \\
\text { into the capsule }\end{array}$ & $\begin{array}{l}\mathrm{R}_{0} \text { surgical } \\
\text { excision }\end{array}$ \\
II & $\begin{array}{l}\mathrm{R}_{0} \text { surgical } \\
\text { excision }+\mathrm{RT}\end{array}$ \\
& $\begin{array}{l}\text { Invasion of the } \\
\text { pericardium, great } \\
\text { vessels, or lung } \\
\text { III }\end{array}$ & $\begin{array}{l}\mathrm{R}_{0} \text { surgical } \\
\text { excision }+\mathrm{RT}\end{array}$ \\
IVA & $\begin{array}{l}\text { Pleural or pericardial } \\
\text { metastatic spread } \\
\text { Pleural or pericardial } \\
\text { IVB }\end{array}$ & $\begin{array}{l}\text { Surgical debulking } \\
+\mathrm{RT}+\mathrm{CHT}\end{array}$ \\
& $\begin{array}{l}\text { Surgical debulking } \\
\text { metastatic spread }\end{array}$ & $+\mathrm{RT}+$ CHT \\
\hline
\end{tabular}

RT radiotherapy; CHT chmiothérapy

Table II World Health Organization: thymoma pathologic classification $[4,5]$

\begin{tabular}{llc}
\hline Type & \multicolumn{1}{c}{ Histologic Description } & DFS $(\%)$ \\
\hline A & Medullary thymoma & 100 \\
AB & Mixed thymoma & 100 \\
B1 & Predominantly cortical thymoma & 83 \\
B2 & Cortical thymoma & 83 \\
B3 & Well-differentiated thymic & 35 \\
C & carcinoma & 28 \\
\hline
\end{tabular}

DFS: 10 years Disease-Free Survival rate

Case reports have documented the use of oral corticosteroids causing regression of an invasive thymoma [12]. In one case, the 
patient showed complete regression of the thymoma and associated symptoms without radiological recurrence after 12 months $[12,13]$.

The initial stage of treatment in most cases of the thymoma is surgery. Surgical resection is the treatment of choice for most neoplasms arising in the mediastinum. In cases of benign lesions the tumor complete excision is generally sufficient. Thymoma is one of the exceptions from this principle because total thymectomy is indicated for all benign or malignant thymoma; the tumor has to be resected without "breaking" the capsule. Surgical excision provides tissue for histological examinations and information on the invasive character of the tumor, which is important to determine the need for an adjuvant therapy. In cases of malignant thymomas, a complete $\mathrm{R}_{0}$ resection should be performed. Pericardium, pleura, lung segments, sternum, ribs and diaphragm can be resected to achieve $R_{0}$ resection in the cases with invasive thymomas [16]. Furthermore brachiocephalic vein and even superior vena cava can be resected; the vascular reconstruction is usually performed using prosthetic grafts $[17,18]$.

The surgery approach is the mid line sternotomy or posterolateral thoracotomy; in invasive thymoma for multivisceral resections the transverse sternotomy extended in $4^{\text {th }}$ intercostals space could be necessary. The video assisted resection is accepted for stage I disease [19].

A single-institution retrospective study was conducted involving 5 patients with stage IVA treated with pleurapneumonectomy [20]. The median survival was 86 months, and the Kaplan-Meier survival was $75 \%$ at 5 years and $50 \%$ at 10 years. There were no operative mortalities in this study. It has been suggested that, in selected patients, this approach, the complete resection after neoadjuvant chemotherapy, may be promising [20].

A multidisciplinary approach to the treatment for inoperable thymoma was also developed. In a study conducted by the MD Anderson Cancer Center, a regimen consisting of the induction chemotherapy, surgical resection, postoperative radiotherapy, and consolidation chemotherapy (e.g. 3 cures of cyclophosphamide, doxorubicin, cisplatin, and prednisone) was tested. [14,15]

\section{CONCLUSIONS}

The prognosis of thymoma depends on tumor histology. The presented cases were Masaoka I stage tumors. The tumors were completely removed and the outcome of the patients was very good with no recurrences for up to 14 years. The lateral approach provides good access and facilitates the resection.

\section{CONFLICT OF INTERESTS}

None to declare

\section{ACKNOWLEDGEMENT}

This paper is partly supported by the Sectorial Operational Programme Human Resources Development (SOP HRD), financed from the European Social Fund and by the Romanian Government under the contract number POSDRU 80641.

\section{REFERENCES}

1. Detterbeck FC, Parsons AM. Thymic tumors. Ann Thorac Surg. 2004; 77(5): 1860-1869.

2. Mullen B, Richardson JD. Primary anterior mediastinal tumors in children and adults. Ann Thorac Surg. 1986; 42(3): 338-345.

3. Falkson CB, Bezjak A, Darling G, et al. The management of thymoma: a systematic review and practice guideline. J Thorac Oncol. 2009; 4(7): 911-919.

4. Kondo K, Yoshizawa K, Tsuyuguchi M, et al. WHO histologic classification is a prognostic indicator in thymoma. Ann Thorac Surg. 2004; 77(4): 1183-1188.

5. Fornasiero A, Daniele O, Ghiotto C, et al. Chemotherapy for invasive thymoma. A 13year experience. Cancer. 1991; 68(1): 30-33.

6. Konstantinov IE, Saxena P, Koniuszko M, et al. Superior vena cava obstruction by tumor thrombus in invasive thymoma: diagnosis and surgical management. Heart Lung Circ. 2007; 16(6):462-464.

7. Blumberg D, Port JL, Weksler B, et al. Thymoma: a multivariate analysis of factors predicting survival. Ann Thorac Surg. 1995; 60(4): 908-913; discussion 914. 
8. Bagga S, Bloch EM. Imaging of an invasive malignant thymoma on PET Scan: CT and histopathologic correlation. Clin Nucl Med. 2006; 31(10): 614-616.

9. Wilkins EW, Grillo HC, Scannell JG, Moncure AC, Mathisen DJ. J. Maxwell Chamberlain Memorial Paper. Role of staging in prognosis and management of thymoma. Ann Thorac Surg. 1991; 51(6): 888-892.

10. Wu KL, Mao JF, Chen GY, et al. Prognostic predictors and long-term outcome of postoperative irradiation in thymoma: a study of 241 patients. Cancer Invest. 2009; 27(10): 1008-1015.

11. Okumura M, Ohta M, Tateyama H, et al. The World Health Organization histologic classification system reflects the oncologic behavior of thymoma: a clinical study of 273 patients. Cancer. 2002; 94(3): 624-632.

12. Barratt S, Puthucheary ZA, Plummeridge M. Complete regression of a thymoma to glucocorticoids, commenced for palliation of symptoms. Eur J Cardiothorac Surg. 2007; 31(6): 1142-1143.

13. Fujiwara T, Mizobuchi T, Shibuya K, Hiroshima K, Fujisawa T, Iwai N. Rapid regression of stage $\mathrm{IVb}$ invasive thymoma under palliative corticosteroid administration. Gen Thorac Cardiovasc Surg. 2007; 55(4): 180-183.
14. Shin DM, Walsh GL, Komaki R, et al. A multidisciplinary approach to therapy for unresectable malignant thymoma. Ann Intern Med. 1998; 129(2): 100-104.

15. Engels EA, Pfeiffer RM. Malignant thymoma in the United States: demographic patterns in incidence and associations with subsequent malignancies. Int J Cancer. 2003; 105(4): 546551.

16. Dango S, Passlick B, Thiemann U, et al. The role of a pseudocapsula in thymic epithelial tumors: outcome and correlation with established prognostic parameters. Results of a 20-year single center retrospective analysis. $J$ Cardiothorac Surg. 2009; 4(1): 33.

17. Gonzalez M, Krueger T, Perentes JY, Matzinger O, Peters S, Ris HB. Extrapleural pneumonectomy with venous confluence resection for stage IVA thymic tumors. Ann Thorac Surg. 2011; 91(3): 941-943.

18. Arvind K, Roman D, Umashankkar K, Pramod KJ, Shiv KC, Neeti M. Resection and reconstruction of mediastinal great vessels in invasive thymoma. Indian J Cancer. 2010; 47(4): 400-405.

19. Venuta F, Anile M, Diso D, et al. Thymoma and thymic carcinoma. Eur J Cardiothorac Surg. 2010; 37(1): 13-25.

20. Wright CD. Pleuropneumonectomy for the treatment of Masaoka stage IVA thymoma. Ann ThoracSurg. 2006; 82(4):1234-1239. 